\title{
Does patient sex play a role in treatment-free remission in chronic myeloid leukemia?
}

\author{
Hiroshi Ureshino $0^{1,2} \cdot$ Kazuharu Kamachi $^{1,2} \cdot$ Shinya Kimura ${ }^{1,2}$ \\ Received: 16 February 2020 / Revised: 8 March 2020 / Accepted: 11 March 2020 / Published online: 21 March 2020 \\ (c) Japanese Society of Hematology 2020
}

Yamaguchi et al. reported treatment-free remission (TFR) after discontinuation of front-line dasatinib in patients with chronic myeloid leukemia (CML) [1]. The TFR appeared to be lower than that in recent tyrosine kinase inhibitor (TKI) discontinuation studies, especially in studies similar to that of first-line DADI (TFR 55.8\% at 1 year) and DASFREE (TFR 54\% at 1 year in front-line dasatinib patients) trials [2, 3]. Although male sex was reportedly a favorable prognostic factor for TFR in the STIM trial, patient sex did not affect TFR in the majority of TKI discontinuation trials. The clinical impact of sex differences, especially those derived from sex-specific immune responses to CML, have not been fully elucidated in patients with CML. Male and female patients were approximately equally enrolled in the first-line DADI and DASFREE trials, whereas female patients that discontinued TKIs were predominantly enrolled in the D-NewS Study. Whether patient sex differences were involved in the decrease in TFR remains unknown.

\section{Compliance with ethical standards}

Conflict of interest S. Kimura received research grants and lecture fees from Bristol-Myers Squibb, Pfizer and Novartis Pharmaceuticals. The other authors declare no conflicts of interest (COI).

\section{References}

1. Yamaguchi H, Takezako N, Ohashi K, Oba K, Kumagai T, Kozai $\mathrm{Y}$, et al. Treatment-free remission after first-line dasatinib treatment in patients with chronic myeloid leukemia in the chronic phase: the D-NewS Study of the Kanto CML Study Group. Int J Hematol. 2020;111:401-8.

2. Kimura S, Imagawa J, Murai K, Hino M, Kitawaki T, Okada M, et al. Treatment-free remission after first-line dasatinib discontinuation in patients with chronic myeloid leukaemia (first-line DADI trial): a single-arm, multicentre, phase 2 trial. Lancet Haematol. 2020;7:e218-225.

3. Shah NP, García-Gutiérrez V, Jiménez-Velasco A, Larson S, Saussele S, Rea D, et al. Dasatinib discontinuation in patients with chronic-phase chronic myeloid leukemia and stable deep molecular response: the DASFREE study. Leuk Lymphoma. 2020;61:650-9.

Publisher's Note Springer Nature remains neutral with regard to jurisdictional claims in published maps and institutional affiliations.

Hiroshi Ureshino

sr0795@cc.saga-u.ac.jp

1 Division of Hematology, Respiratory Medicine and Oncology, Department of Internal Medicine, Saga University, 5-1-1 Nabeshima, Saga 849-8501, Japan

2 Department of Drug Discovery and Biomedical Sciences, Saga University, Saga, Japan 